\title{
A INSERÇÃO DE MATÉRIAS JURÍDICAS NA GRADE CURRICULAR DAS SÉRIES FINAIS DO ENSINO FUNDAMENTAL DAS ESCOLAS PÚBLICAS DE MARINGÁ
}

\author{
Nilvânia Pereira da Silva Moreira ${ }^{1}$
}

RESUMO: Este trabalho tem como objetivo identificar, sob a ótica dos gestores de escolas públicas de Maringá, a importância da inclusão de conteúdos jurídicos na grade curricular do ensino fundamental. Para tanto, os procedimentos metodológicos compreenderam a pesquisa qualitativa, bibliográfica e de campo. Foram coletados dados primários e secundários, sendo estes obtidos por meio de documentos disponíveis no site da Secretaria da Educação do Estado do Paraná. Os dados primários foram obtidos por meio de um questionário estruturado, composto de in questões abertas e uma fechada. Por meio de análise interpretativa buscou-se identificar elementos que pudessem explicar a importância da inserção de matérias jurídicas no ensino fundamental das escolas públicas. Os resultados revelaram que não existe uma disciplina jurídica, contudo, alguns conteúdos relacionados a essa temática que são introduzidos de forma interdisciplinar. A maioria dos coordenadores e diretores considerou importante investir numa proposta dessa natureza, pois contribuiria para a formação da cidadania e informação de direitos básicos ao aluno. Em contrapartida, relataram que seria difícil enquadrar mais uma disciplina na grade curricular, tendo em vista que não há mais espaço devido a quantidade de disciplina já existente no ensino fundamental. Assim, a partir de estudos que apontam medidas já implementadas em alguns Estados, contatou-se a importância da inclusão de uma disciplina de noções básicas de direito nas escolas públicas de Maringá.

Palavras-chave. Ensino Fundamental. Disciplina Jurídica. Currículo.

\section{INTRODUÇÃO}

A educação é um fenômeno que acompanha o ser humano ao longo de toda sua vida. Ela é crucial para a humanização do ser humano, para o desenvolvimento do seu projeto de vida e mesmo do projeto antropológico da humanidade (CARVALHO, 200I). Trata-se de um direito fundamental que ajuda não só no desenvolvimento de um país, mas

\footnotetext{
${ }^{\text {I }}$ Pós- Graduação em Direito do Trabalho e Direito Previdenciário do Instituto de Direito Constitucional e Cidadania (IDCC). Atuou como professora do Ensino Fundamental pela Prefeitura Municipal de Maringá; atuou como professora do Ensino Fundamental na Sociedade de Educação e Cultura de Porto Velho e professora na Inspetoria Salesiana Missionária da Amazônia em Porto Velho.Graduada em Direito pela Faculdade Maringá; possui Graduação em Pedagogia pela Universidade Estadual de Maringá Atualmente é advogada com inscrição na OAB/PR. É membro da Comissão de Direito do Trabalho da OAB Maringá. Email: advogada_nilvania@outlook.com.
} 
também de cada indivíduo. Por meio da educação garantimos nosso desenvolvimento social, econômico e cultural.

Nesse sentido, o artigo 205 da Constituição Federal/88 estabelece que "a educação, direito de todos e dever do Estado e da família, será promovida e incentivada com a colaboração da sociedade, visando o pleno desenvolvimento da pessoa, seu preparo para o exercício da cidadania e sua qualificação para o trabalho".

Por sua vez, a Lei que estabelece as Diretrizes e Bases da Educação Nacional (LDB), Lei no 9394, de 20 de dezembro de 1996, aponta, em seu artigo Io, que "a educação abrange os processos formativos que se desenvolvem na vida familiar, na convivência humana, no trabalho, nas instituições de ensino e pesquisa, nos movimentos sociais e organizações da sociedade civil e nas manifestações culturais".

Nesse contexto, a escola tem papel fundamental, uma vez que seu foco principal é a preparação do aluno para a vida, para o convívio em sociedade. Sendo assim, o acesso a informações jurídicas desde o ensino fundamental seria de relevante significado para o cidadão no sentido de contribuir para o exercício da cidadania, para instruir melhor as pessoas que estariam mais bem preparadas para lidar com situações do dia-a-dia, sem contar com o crescimento intelectual e humanístico dos estudantes. Portanto, acredita-se que as informações jurídicas devem ser repassadas desde cedo nas escolas públicas de ensino fundamental, visando assim a um melhor exercício da cidadania.

Desta forma, esta pesquisa teve por objetivo identificar, sob a ótica dos gestores de escolas públicas de Maringá, a importância da inclusão de conteúdos jurídicos na grade curricular do ensino fundamental.

Para tanto, os procedimentos metodológicos compreenderam a pesquisa qualitativa, bibliográfica e de campo. Foram coletados dados primários e secundários, sendo estes obtidos por meio de documentos disponíveis no site da Secretaria da Educação do Estado do Paraná. Os dados primários foram obtidos por meio de um questionário estruturado, composto de II questões abertas e uma fechada. Os participantes da pesquisa foram identificados por meio de informações fornecidas pela Secretaria de Educação de Maringá, as quais revelaram que na cidade existem 33 escolas públicas que oferecem ensino fundamental. 
Antes de proceder ao envio dos questionários, foi efetuado contato telefônico com os diretores das escolas com vistas a explicar os objetivos do estudo e assegurar a livre adesão à pesquisa. Posteriormente, foram enviados os questionários em anexo a correspondências eletrônicas e/ou entregues pessoalmente, para preenchimento dos diretores ou coordenadores das escolas. Por meio de análise interpretativa buscou-se identificar elementos que pudessem explicar a importância da inserção de matérias jurídicas no ensino fundamental das escolas públicas.

Este estudo encontra-se organizado em seis seções. Além desta Introdução, apresenta-se uma abordagem teórica sucinta sobre cidadania, currículo e acesso à educação jurídica, seguida da apresentação dos resultados da pesquisa e das considerações finais.

\section{CIDADANIA COMO PARTICIPAÇÃO SOCIAL E POLÍTICA}

Ante os múltiplos desafios do futuro, a educação surge como um triunfo indispensável à humanidade na sua construção de bons ideais, como liberdade, justiça social e outros. Os sistemas educativos devem dar respostas aos múltiplos desafios das sociedades, na perspectiva de um enriquecimento contínuo dos saberes e do exercício de uma cidadania adaptada às exigências do nosso tempo ${ }^{2}$.

A Comissão Internacional sobre Educação para o Século XXI expõe que o ensino deve garantir que o aluno venha a exprimir-se com toda independência e responsabilidade acerca dos problemas éticos e sociais como uma espécie de poder intelectual necessário para ajudar a sociedade a refletir, compreender e agir ${ }^{3}$.

O aluno deve assumir as suas responsabilidades em relação aos outros. Há, pois, que preparar cada pessoa que passa pela escola para esta participação, mostrando-lhes seus direitos e deveres.

O Relatório para a UNESCO, por exemplo, deixa claro que o sistema educativo tem por missão preparar cada um para assumir papel social, onde no dia-a-dia, na vida profissional, cultural, associativa, de consumidor, cada membro da coletividade deve assumir as suas responsabilidades.

2 EDUCAÇÃ̃: um tesouro a descobrir. ı.ed. São Paulo: Cortez; Brasília, DF:MEC: UNESCO, 2006. Relatório para a UNESCO da Comissão Internacional sobre Educação para o Século XXI. p.68. 3 Ibidem, p. Iso. 
A preparação para uma participação ativa na vida de cidadão tornou-se para a educação uma missão de caráter geral, uma vez que os princípios democráticos se expandiram pelo mundo ${ }^{4}$.

O compromisso com a construção da cidadania pede uma prática educacional voltada para a compreensão da realidade social, eis a importância de instruir os alunos com noções de direito visando a efetividade desses direitos.

\section{CURRÍCULO COMO GARANTIA DE DIREITO}

$\mathrm{Na}$ área da educação o campo do currículo traz discussões polissêmicas enraizadas em discursos e práticas de variados espaços e tempos históricos. Sabe-se que o currículo está sempre em construção e deve ser compreendido como um processo contínuo.

A noção de currículo acaba reduzida quase sempre ao elenco ou à disposição de conteúdos escolares. Sendo o currículo uma prática social que agrega a diversidade humana, não é estranho encontrarmos sentidos tão diferentes, seja na educação propriamente dita, no campo social mais amplo, ou nos campos de lutas políticas e das práticas culturais ${ }^{5}$.

Para muitos autores os currículos são uma construção e seleção de conhecimentos e práticas produzidas no contexto real da sociedade, abrangendo as questões sociais, políticas, culturais e pedagógicas. Portanto, além dos conteúdos selecionados, devem-se levar em conta as necessidades dos alunos, sua realidade social e diversidade cultural, como estabelece o artigo 26 da LDB.

Nunca se constatou na história da educação tamanha importância atribuída às políticas e propostas curriculares. Se levarmos em conta o contexto de importância que o currículo assume no mundo, em termos da concepção e da construção contemporânea das formações, o seu empoderamento político-pedagógico, assim como a complexidade que emerge dessas configurações, a explicitação reflexiva do campo curricular e da noção de

\footnotetext{
4 Ibidem, p. 6r.

${ }^{5}$ ROCHA, Aline Andrade Weber Nunes da Rocha. Currículos: Teorias e Práticas. RAMAL; Andrea; SANTOS, Ednéa Oliveira dos (ORg.) Rio de Janeiro: LCT, 2012. Prefácio.
} 
currículo (no sentido de distinguir histórica e conceitualmente as perspectivas e as práticas) se torna uma responsabilidade formativa social e pedagógica incontestável ${ }^{6}$.

Com a promulgação da Lei $9 \cdot 394 / 96$, as escolas adquiriram o direito da elaboração coletiva do Projeto Político Pedagógico. Em seu artigo 12, inciso I, essa lei dispõe que: "os estabelecimentos de ensino, respeitadas as normas comuns e as do seu sistema de ensino, terão a incumbência de: I - elaborar e executar sua proposta pedagógica"7.

Interessa desde já perceber que o Plano Nacional de Educação (Lei 13005, de 2014), contempla entre suas metas prioritárias a necessidade de elaboração de uma Base Nacional Curricular Comum, na verdade reiterando a própria LDB, que, em seu artigo 26, incumbia a União dessa tarefa, já determinando a observação de espaço para uma parte diversificada ${ }^{8}$.

Como se percebe, o currículo torna-se um instrumento de escolhas; nele os conhecimentos são separados, algo fica dentro e algo fora. Essas divisões são parte de relações de poder que refletem o que deve e o que não deve ser ensinado, determinando o que passa por conhecimento válido, incluindo certos saberes, estabelecendo diferenças, construindo hierarquias e produzindo subjetividades ${ }^{9}$.

Feitas essa considerações, faz-se necessário mencionar que os componentes curriculares das escolas de Maringá, especialmente do Ensino Fundamental, destacam que os objetivos educacionais estão pautados na compreensão do ambiente natural e social, do sistema político, da economia, da tecnologia, das artes, da cultura e dos valores em que se fundamenta a sociedade; no desenvolvimento da capacidade de aprendizagem, tendo em vista a aquisição de conhecimentos e habilidades e a formação de atitudes e valores ${ }^{\text {Io }}$.

\footnotetext{
${ }^{6}$ Ibidem, cap.I.

${ }^{7}$ BRASIL. Ministério da Educação. Secretaria de Educação Básica. Departamento de Políticas de Educação Infantil e Ensino Fundamental. Indagações sobre currículo: Currículo, Conhecimento e Cultura. Brasilia, 2007. p 48. Disponível em: 〈http//portal.mec.gov.br/seb/arquivos/pdf/Ensfund/indag5.pdf〉. Acesso em: 04 maio 2016.

${ }^{8}$ PRESIDENTE do Consed fala sobre o Seminário sobre a Base na Comissão de Educação da Câmara. Disponível em: 〈http://basenacionalcomum.mec.gov.br/\#/site/noticias/capa?noticia=3323〉. Acesso em: 14 abr. 2016.

9 PARANÁ. Secretaria da Educação. Diretrizes Curriculares de Gênero e Diversidade Sexual da Secretaria de Estado da Educação do Paraná. 2oro. Disponível em: 〈http://www.educadores.diaadia.pr.gov.br/arquivos/File/pdf/dce_diversidade.pdf〉. Acesso em: 19 set. 2016. io PARANÁ Secretaria da Educação. Ensino Fundamental - Anos Finais. Disponível em: 〈http://www.educadores.diaadia.pr.gov.br/modules/conteudo/conteudo.php?conteudo=769〉. Acesso em: 19 set. 2016.
} 
Esses objetivos deixam evidente a importância de desenvolver no aluno a compreensão do ambiente social, político e econômico. No entanto, para que isso ocorra de forma mais eficaz, uma disciplina única, como noções de direito, daria conta de trabalhar com os alunos conteúdos jurídicos, de modo a abarcar mais conteúdos voltados ao exercício responsável da cidadania.

As Diretrizes Curriculares para a Educação Pública do Estado do Paraná é um documento oficial que se insere em todas as escolas e Núcleos Regionais de Educação do Estado, e já conta com alguns conteúdos importantes, mas que são trabalhados de maneira interdisciplinar e com pouca frequência devido as diversas disciplinas já existentes.

Assim sendo, importante seria apostar em mudanças nos currículos das escolas, de modo a proporcionar um estudo mais aprofundado dos assuntos já apontados, como: Direitos Humanos, Educação Ambiental, Justiça e Participação Social, Noções de Direito Constitucional, Noções de Direito do Trabalho, Noções de Direito Civil, Noções de Direito do Consumidor, dentre outras que se fizerem necessárias.

\section{ACESSO À EDUCAÇÃO JURÍDICA: FORMAÇÃO INDISPENSÁVEL PARA O EXERCÍCIO DA CIDADANIA}

O artigo $5^{\circ}$ da Constituição Federal, em seu capítulo II, garante uma lista de direitos civis, dentre os quais muitos têm a ver com educação, como por exemplo, igualdade jurídica entre homem e mulher, liberdade de consciência e de expressão, dentre outros.

Sendo assim, para que o aluno aprenda desde cedo a posicionar-se de maneira crítica e responsável, é necessário que compreenda a cidadania como participação social e política. Para tanto, precisa conhecer seus direitos e deveres. Essa construção da cidadania passa necessariamente pela prática educacional e consequentemente pelo currículo ${ }^{\mathrm{II}}$.

Como mencionado acima, o currículo desempenha papel fundamental, uma vez que cria expectativas de aprendizagem expressando aquilo que é considerado importante para o desenvolvimento intelectual do aluno.

\footnotetext{
${ }^{\text {II }}$ FERNANDES, Maria Cristina da Silveira Galan; COSTA, Alessandra David Moreira da; SICCA, Natalina Aparecida Laguna (Org). Currículo, história e poder. Florianópolis: Insular, 2006.
} 
Atualmente, os documentos que norteiam a educação básica são a LDB, as Diretrizes Curriculares Nacionais para Educação Básica e o Plano Nacional de Educação. Outros documentos fundamentais são a Constituição da República Federativa do Brasil e o Estatuto da Criança e do Adolescente ${ }^{\mathrm{I} 2}$.

Apesar de haver previsão explícita, nesses documentos, da necessidade de incorporar temas acerca das relações sociais no currículo, não existe uma disciplina que forneça ao aluno o conteúdo necessário que leve à compreensão da cidadania como participação social e política, assim como ao exercício de direitos e deveres políticos, civis e sociais.

Nas Metas e Estratégias do Plano Estadual de Educação do Paraná, faz-se a leitura de artigo da Lei Federal no. 13.005/2014, que aprova o Plano Nacional de Educação, em seu Art. 2. , inciso $\mathrm{X}$, e define como diretrizes para a educação brasileira a promoção dos princípios do respeito aos direitos humanos, à diversidade e à sustentabilidade socioambiental ${ }^{13}$.

Para reforçar a importância da inclusão de noções de direito nas redes públicas, o Projeto de Lei no.r.029/2015 tem por finalidade instituir noções de direito nas redes públicas e privadas de ensino fundamental e médio, sugerindo matérias de Direitos Humanos, Noções de Direito Constitucional, Direito do Trabalho, Direito Civil, Direito do Consumidor, para que sejam incluídas nos currículos do ensino médio das escolas públicas e privadas.

Os assuntos apresentados no Projeto de Lei, assim como os indicados nos cadernos temáticos da Secretaria Estadual de Educação de Maringá, constituem temas importantes que deveriam ser desenvolvidos em sala de aula.

Em pesquisa em sites da internet, constatou-se que alguns Estados, como Mato Grosso, Rondônia, São Paulo, Minas Gerais, possuem um projeto de lei aprovado que contempla discussões sobre a inserção de matérias jurídicas no ensino médio e

I2BRASIL. Ministério da Educação. Secretaria da Educação Básica. Disponível em: 〈http://portal.mec.gov.br/index.php?option=com_content\&view=article\&id=293\&Itemid=358>. Acesso em: o6 maio 2016

I3 PARANÁ. Plano Estadual de Educação do Paraná. Disponível em: 〈http://www.educacao.pr.gov.br/arquivos/File/PEE/PEEPR_ANEXO_UNICO.pdf〉. Acesso em: o4 maio 2016. 
fundamental. No Estado de Rondônia, por exemplo, a fonte de inspiração para a inclusão de noções básicas de direito nas escolas partiu da Ordem dos Advogados do Brasil (OAB).

Existem também projetos Implementados em algumas escolas do Brasil, como o ECA vai à escola, OAB vai à escola, Trabalho, Justiça e Cidadania, idealizado pela Associação Nacional dos Magistrados (Site da ANAMATRA), dentre outros. ${ }^{14}$

Conclui-se, da análise dos documentos norteadores da educação, bem como das Diretrizes Curriculares de Maringá, em especial dos cadernos temáticos voltados para os conteúdos que abordam assuntos de direito, que deveria haver um espaço na grade curricular para essas questões, o que poderia ocorrer por meio da inclusão de uma disciplina jurídica na grade curricular.

\section{RESULTADOS DA PESQUISA}

A partir do retorno dos questionários enviados aos diretores ou coordenadores de escolas públicas de Maringá que oferecem ensino fundamental, que totalizou 21\%, ficou evidente que esses gestores admitem a importância dos conteúdos propostos pelos cadernos temáticos da Secretaria Estadual de Educação e os indicados pelo Projeto de Lei no I.029/2015, mas não veem possibilidade da inclusão de mais uma disciplina, dado o grande número já existente na grade curricular, quais sejam, Arte, Educação Física, Língua Estrangeira, Química, Física, Biologia, Ensino Religioso, Geografia, Língua Portuguesa, Sociologia, Ciências, Filosofia, História e Matemática, disciplinas essas de tradição curricular.

Por meio da pesquisa observou-se ainda que não existe uma disciplina na grade curricular para ensinar noções básicas de direito ${ }^{15}$. $\mathrm{Na}$ realidade, quando se desenvolve algum debate envolvendo assunto jurídico, isso ocorre de forma interdisciplinar, por meio de interações, diálogos estabelecidos no espaço escolar por diferentes disciplinas.

${ }^{14}$ ASSEMBLEIA aprova projeto de noções de Direito nas escolas. Disponível em: <http://www.gentedeopiniao.com.br/noticia/assembleia-aprova-projeto-de-noçoes-de-direito-nasescolas/roooo4>. Acesso em: 07 jun. 2016.

is PARANÁ. Secretaria de Educação. Diretrizes. Disponível em: 〈http://www.educadores.diaadia.pr.gov.br/modules/conteudo/conteudo.php?conteudo=I $>$. Acesso em: II maio 2016. 
Da constatação de que não existe uma disciplina jurídica na grade curricular e por ser o ensino fundamental importantíssimo para o desenvolvimento do aluno, ficou evidente que se deve possibilitar aos mesmos, ainda nessa fase educacional, condições para o exercício da liberdade, da participação política e da cidadania.

Juntamente com as Diretrizes Curriculares do Ensino Fundamental das escolas públicas de Maringá, são apresentados como recursos didáticos os cadernos temáticos, entre eles os de Direitos Humanos, Educação Ambiental, Justiça e Participação Social. Esses temas são de grande importância e deveriam ser contemplados em uma disciplina jurídica, ganhando espaço na grade curricular das escolas de Maringá ${ }^{16}$.

Os resultados da pesquisa apontam ainda que a inclusão de uma disciplina jurídica nas escolas estaduais demandaria tempo e teria que acontecer de forma gradativa, com debates entre os educadores e autorização de órgãos competentes. Dentre os conteúdos que poderiam ser inclusos na grade curricular, noções de direitos humanos foi apontado pelos gestores como o mais necessário.

Apesar dos coordenadores e educadores concordarem que o assunto em tese é importante, e de haver previsão explícita da necessidade de incorporar temas jurídicos, certo é que não é fornecido ao aluno conteúdo teórico necessário para sua formação cidadã, deixando, assim, de cumprir os objetivos almejados pelos documentos, em especial a LDB.

\section{CONSIDERAÇÕES FINAIS}

O objetivo deste estudo foi identificar, sob a ótica dos gestores de escolas públicas de Maringá, a importância da inclusão de conteúdos jurídicos na grade curricular do ensino fundamental. Assim, os resultados da pesquisa revelaram que a incorporação de temas jurídicos é de fundamental importância, contudo, conteúdos relacionados às noções de direitos humanos foi apontado como extremamente necessário no momento.

$\mathrm{Da}$ análise das Diretrizes Curriculares, verificou-se que não se tem investido em novas propostas que possam oportunizar condições para que temas socialmente relevantes sejam incluídos nos currículos escolares.

I6 PARANÁ. Secretaria de Educação. Recursos Didáticos,. Disponível em: 〈http://www.educadores.diaadia.pr.gov.br/modules/conteudo/conteudo.php?conteudo=3〉. Acesso em: o6 maio 2016. 
Conforme se depreende dos documentos norteadores da educação, bem como dos currículos das escolas de Maringá, conclui-se que o objetivo mínimo a ser alcançado no ensino fundamental atende mais a um papel social em função de códigos estabelecidos do que a um papel que leve o aluno a argumentar sobre a atual crise de valores, tendo como exemplo o atual cenário de corrupção. Assim, em termos políticos, uma disciplina jurídica nas escolas, também, poderá ser um grito contra os atuais acontecimentos no âmbito político $^{17}$.

Por meio de reflexões, aumentou-se a conviç̧ão da importância de adaptar o currículo às novas exigências da atualidade, pois como se disse, os sistemas educativos devem dar respostas aos múltiplos desafios da sociedade.

A inclusão de uma disciplina que aborde temas de direito no currículo escolar irá proporcionar ao aluno o conhecimento dos seus direitos e deveres, como por exemplo, direito à liberdade, saúde, educação, direito de votar, respeitar os direitos sociais de outras pessoas, proteção da natureza, proteção do patrimônio público, e muitos outros contidos na Constituição Federal.

\section{REFERÊNCIAS}

BRASIL. Ministério da Educação. Secretaria da Educação Básica. Disponível em: $\langle$ http://portal.mec.gov.br/index.php?option=com_content $\&$ view $=$ article $\&$ id $=293 \&$ Itemid $=$ 358>. Acesso em: o6 maio 2016.

BRASIL. Ministério da Educação. Secretaria de Educação Básica. Departamento de Políticas de Educação Infantil e Ensino Fundamental. Indagações sobre currículo: Currículo, Conhecimento e Cultura. Brasília, 2007. Disponível em: $\langle$ http//portal.mec.gov.br/seb/arquivos/pdf/Ensfund/indag5.pdf〉. Acesso em: o4 maio 2016.

EDUCAÇÃO: um tesouro a descobrir. ro.ed. São Paulo: Cortez; Brasília, DF:MEC: UNESCO, 2006. Relatório para a UNESCO da Comissão Internacional sobre Educação para o Século XXI. p.68.

${ }_{17} \mathrm{NETO}$, L. Educadores criticam inclusão de ética e cidadania no currículo. Disponível em: <http://oglobo.globo.com/sociedade/educacao/educadores-criticam-inclusao-de-etica-cidadania-nocurriculo-6991486\#ixzz4DJGwNiOD>. Acesso em: o7 jun. 2016. 
FERNANDES, Maria Cristina da Silveira Galan; COSTA, Alessandra David Moreira da; SICCA, Natalina Aparecida Laguna (Org). Currículo, história e poder. Florianópolis: Insular, 2006.

NETO, L. Educadores criticam inclusão de ética e cidadania no currículo. Disponível em: <http://oglobo.globo.com/sociedade/educacao/educadores-criticam-inclusao-de-eticacidadania-no-curriculo-6991486\#ixzz4DJGwNiOD>. Acesso em: o7 jun. 2016.

PARANÁ. Secretaria de Educação. Diretrizes. Disponível em: $\langle$ http://www.educadores.diaadia.pr.gov.br/modules/conteudo/conteudo.php? conteudo=I $>$ . Acesso em: II maio 2016.

PARANÁ. Plano Estadual de Educação do Paraná. Disponível em: $\langle$ http://www.educacao.pr.gov.br/arquivos/File/PEE/PEEPR_ANEXO_UNICO.pdf〉. Acesso em: 04 maio 2016.

PARANÁ. Secretaria da Educação. Diretrizes Curriculares de Gênero e Diversidade Sexual da Secretaria de Estado da Educação do Paraná. 2010. Disponível em: $\langle$ http://www.educadores.diaadia.pr.gov.br/arquivos/File/pdf/dce_diversidade.pdf〉.

Acesso em: 19 set. 2016.

PARANÁ Secretaria da Educação. Ensino Fundamental - Anos Finais. Disponível em: <http://www.educadores.diaadia.pr.gov.br/modules/conteudo/conteudo.php?conteudo=7 69>. Acesso em: 19 set. 2016.

PARANÁ. Secretaria de Educação. Recursos Didáticos. Disponível em: 〈http://www.educadores.diaadia.pr.gov.br/modules/conteudo/conteudo.php? conteudo=3〉 . Acesso em: o6 maio 2016.

PRESIDENTE do Consed fala sobre o Seminário sobre a Base na Comissão de Educação da Câmara. Disponível em: $\langle$ http://basenacionalcomum.mec.gov.br/\#/site/noticias/capa?noticia=3323 $\rangle$. Acesso em: I4 abr. 2016.

ROCHA, Aline Andrade Weber Nunes da Rocha. Currículos: Teorias e Práticas. RAMAL; Andrea; SANTOS, Ednéa Oliveira dos (ORg.) Rio de Janeiro: LCT, 2012. Prefácio. 